\title{
Contemplating Design: Listening to Children's Preferences about Classroom Design
}

\author{
Marilyn A. Read \\ Department of Design and Human Environment, Oregon State University, Corvallis, USA \\ Email: Marilyn.read@oregonstate.edu
}

Received June $29^{\text {th }}$, 2010; revised July 22 ${ }^{\text {nd }}, 2010$; accepted July 30 $0^{\text {th }}, 2010$.

\begin{abstract}
This paper focuses on children's responses about the design of two images of interior classroom environments. Children reported that key elements were circles, spheres, and windows in the low visual stimulation environment. In the high visual stimulation environment they identified activity materials and the decor as preferred elements in the space. Results from this study can be used by designers of child development centers to guide the design of the space to reflect one that incorporates children's preferences for design.
\end{abstract}

Keywords: Classroom Environments, Design Principles and Elements

\section{Introduction}

Young children understand and appreciate the aesthetics of their near environment in both a complex and visceral manner. As they work on projects, create new experiences, eat lunch and rest, their eyes are scanning and focusing on the designed classroom environment. Visual stimuli within a space can vary widely from high visual stimulation which may appear to the young child as cluttered and overwhelming to low visual stimulation which may appear boring and static. Interior design principles and elements in the classroom range from bright and subdued colors of materials and manipulative to rich and varied textures on the furnishings, walls, floor, ceiling, and cabinetry. The aesthetics are enhanced with myriad shapes, forms, and light throughout that add to the richness, complexity, and depth of the space. Ideally, the synthesis of functional and aesthetic components in the classroom creates a harmonious setting for young children. Researchers have extensively studied visual perceptual knowledge of children [1]. The area that has not been investigated is the impact of aesthetic form and finishes on children's preferences.

Numerous decisions about the application of the elements and principles of design in the classroom are determined primarily by the teachers in the setting. Possible questions teachers may ask themselves when designing the classroom include the following: 1) Does my classroom design reflect a welcoming learning environment?
2) Does my classroom design represent the curriculum or theoretical perspective of the center? 3) How do the children in my class perceive the designed classroom? and 4) What type of design characteristics do children in the environment prefer and why? The focus of this study was concerned with the last two questions regarding children's perceptions and preferences in the classroom environment. Specifically, the researcher was investigating children's preferences for an environment with design elements and principles illustrating a space with low visual stimulation versus a high visual stimulation environment. The overall objective of the research project was to have a better understanding of what principles and elements of design are considered to be aesthetically pleasing to young children.

\section{Background}

Enclosed space provides a backdrop for combining complex and meaningful design elements and design principles. "In the large literature on environmental quality, relatively few works attempt to understand how people feel about space and place, to take into account the different modes of experience (sensorimotor, tactile, visual, conceptual), and to interpret space and place as images of complex —often ambivalent-feelings"-Yi-Fu Tuan. [2]

Tuan highlights the idea that space is somewhat minimized and underappreciated as a salient concept. Young children report detailed knowledge of the various shapes, forms, and colors in the near environment; however, the 
meaning of these elements of design to children is unclear. Malnar and Vodvarka [3] propose that sensation is mediated by culture and experience to form an individual's reaction to space. This proposition places sensory experiences as the central concept that impacts a person's response to their environments.

Principles and elements are usually represented in the use and manipulation of materials. The interaction of the elements of line, shape, form, pattern, texture, scale, light, and color with the principles of proportion, balance, rhythm, contrast, emphasis, and harmony creates the overall aesthetic effect of the space.

The direction of a line can be horizontal, vertical, diagonal, or curvilinear. Horizontal lines are usually thought to evoke feelings of calm, rest and stability within a space. Lines in the early childhood classroom can often be seen in the division of a wall with one horizontal line separating the upper and lower walls with paint and a chair rail. This design is useful when the ceiling in a space is high. A visually lowered ceiling is scaled to and reflective of a child's height. Vertical lines show strength with resistance to gravity $[4,5]$.

Images of vertical lines are created with tall windows, paint, columns, and wall variations with the application of different materials to emphasize height. Diagonal lines suggest a dynamic motion or tension within a space creating a sense of movement. They are best used in areas where children's play is highly active. Curvilinear lines also create visual motion; however, they have a softer effect that has a flow or rhythm as compared to diagonal lines. In a recent study, Dazkir [6] found that people reported curvilinear lines in furniture to be more pleasing than furniture with rectilinear lines. It may be that children would prefer curvilinear lines to rectilinear lines as pleasing design elements in a space.

The elements associated with shape such as square, circle, rectangle and triangle have similar associations to line. The circle is considered to be a more inviting, calming shape while the square and rectangle are more rigid with their rectilinear shapes and sharp corners. The triangle is dynamic with its diagonal lines but also rigid and uninviting with its sharp corners. Cubes are stable while spheres evoke feelings of movement while a pyramid form shows stability with dynamic diagonal edges. Organic shapes, based on the natural environment, are amorphous without clearly defined shapes. Organic designs denote movement with their curvilinear, asymmetrical line and form. They can be quite effectively in a space to show variation from symmetrical geometric shapes and forms.

The additional elements of color, light, texture, pattern, and scale complete the design of the space. Variety of texture and pattern can create a high visual stimulation environment or a low visual stimulation environment depending on the materials used to create the texture or pattern. For more information on children's color preferences, please see Read and Upington [7].

The natural light in a space is critical to children's proper physical development [8]. Windows add visual interest with transparency, reflection, views, and spatial variation [9] while providing views to the outside helping children with understanding of climate patterns, natural cycles, and different times of the year.

If the center can provide views to green space, children will benefit from the opportunity to gaze at the natural environment [10]. Ideally, a center will have windows on opposite sides of the room to balance the glare and reflection within the space. Clearly the principles and elements of design create an environment that can be dynamic or serene depending on how they are implemented in the design of the space.

\section{Evaluations of Children's Environments}

The designed classroom is seldom the central focus of observational research with children. For example, Boehm and Weinberg [11] detailed methods for observing children within the classroom environment, however, the descriptions of the classroom focused solely on the furniture layout and lighting in the space.

Interior design elements and principles were not incorporated in the observation guidelines. The ECERS-R scale [12] is used extensively to evaluate classrooms, however, the designed environment is, again, only considered in the context of the furniture layout and materials within the space.

The aesthetics of the physical environment is a significant consideration [13] that, for the most part, has been overlooked in the literature on early childhood education environments.

Interior designers and architects of child development centers do not regularly consider the perspective of the children using the classrooms. Children's perspectives on aesthetics are important for thoughtful inquiry because designers of child development centers are typically using design principles and elements that are pleasing to adults. The center's board of directors, administrators, teachers, parents, architects and / or interior designers may be involved in the design process of the center. The children's perspective on the designed classroom is often overlooked in the design-decision making process. This is unfortunate because young children are passionate observers of the environment and, as such, their reports of preferences for interior design principles and elements are important to understanding their perceptions of the classroom environment. 
Clark, McQuail, and Moss [14] concluded that studies should include listening to children's views on the indoor and outdoor environment. Therefore, this study focuses on children's reports of preferences for two designed environments.

\section{Method}

Twenty-two girls and 23 boys participated in this study. Twenty children were 3-years of age, 21 children were 4-years of age, and four children were 5-years of age. Semi-structured interviews and image selection were used as methods to understand children's design preferences. Each child discussed two photographs with the interviewer while seated at a small table. Two digital images of two different classroom environments were used as the visual stimuli. Figure 1 shows a classroom with low visual stimulation with subdued colors, low shelving, windows, and area for movement. Figure 2 depicts a classroom with high visual stimulation in the space. A variety of display materials are seen with bright colors and assorted shapes along with densely placed chairs and tables. The children were asked to identify which room they would like to visit most. The interviews were designed in an open-ended format so that children would express their preferences without a structured plan from the questionnaire. The interviews were recorded with field notes and audiotapes which were then transcribed and analyzed using coding techniques to draw out themes from the interviews [15].

\section{Results}

The themes that emerged from the children's responses to Figure 1 were Circular and Spherical Design Elements and Windows. Children discussed distinctive design elements when they noted their preferred classroom environment. The classroom in Figure 1 was described as open with a lot of space. It was "plain", "not messy", and had "lots of space to run". The spherical forms and circular shapes throughout the space drew the participants' attention for discussion. Although the balls were partially seen in the lower right-hand corner of the photograph, several children, both boys and girls, commented on these forms as representing something special in the space. As well, they noted the hat above the window and the map of the world. An additional theme that emerged from the children's responses was the description of the windows. Windows are clearly a dominant design element in the photograph so it is not surprising that they were discussed as a special element in the classroom. In this particular photograph, the windows create an asymmetrical rhythm with seven windows on the left wall and three windows on the right wall along with emphasis on the large scale dominance of the space.

\section{Selected children's responses to Figure 1:}

The interviewer question is identified with an $I$ and the Respondent is identified with an $R$. For example $R-6$ refers to respondent 6 .

I. Would you most like to visit this room (point at room 1) or this one (point at room 2)?

What is special about this room?

\section{Circular and Spherical Design Elements}

$\boldsymbol{R}-6$ It has a circle (pointing to map) and a baseball (pointing to orange hat at top of windows). Boy

R-9 Because it looks better and good and it has a picture of two sides of the earth. Yeah, I can see some stuff in the corner right there, and that red circle there by the windows, which I think is Mars, and... there's a tree (small plant on desk in farthest corner) on the table...and it...it doesn't have a clock...and...it's not messy as the other picture. Boy

$\boldsymbol{R}$-32 Points to orange hat on wall, points to colored balls in corner. Points to the map on the wall. Girl

$\boldsymbol{R}-\mathbf{1 3}$ Because this has a circle thing that you can ride on. Maps. The chairs. I think all of the stuff is special. Boy

\section{Windows}

R-7 It has lots of windows. (Points to balls in corner. Points to flowers on desk.) The floor's so big, windows. Girl

$\boldsymbol{R}$-39 Windows, (points to more windows), more windows. Points to balls in right lower corner. Boy

$\boldsymbol{R}-41$ It's plain. Windows. Boy

In Figure 2, the high visual stimulation environment, children preferred the wall decorations, particularly the banner of the children, the musical notes, and the poster of the red dog. The space was described as "fancy", "pretty", "more decorated", and "fun". They also noted the puzzles, blocks, and kitchen play area as special elements in the space. The two themes that emerged from Figure 2 were Décor and Activity Materials.

Selected children's responses to Figure 2:

I. Would you most like to visit this room (point at room 1 ) or this one (point at room 2)?

What is special about this room?

Décor

$\boldsymbol{R}-20$ Because...I really like it, it's not very messy. Well it has these pretty things here. Like chairs, tables, people on the walls and those...(pointing to musical notes on the wall). Boy.

R-21 Well, because there's lots of fancy stuff in it. A lot of fancy stuff in here - this room kind of has more, a lot of, more stuff in it so it looks more fancy. Girl

$\boldsymbol{R}$-35 Because it's more decorated. I like this banner. I like those (pointing to music notes) and these stickers on the wall. Girl 


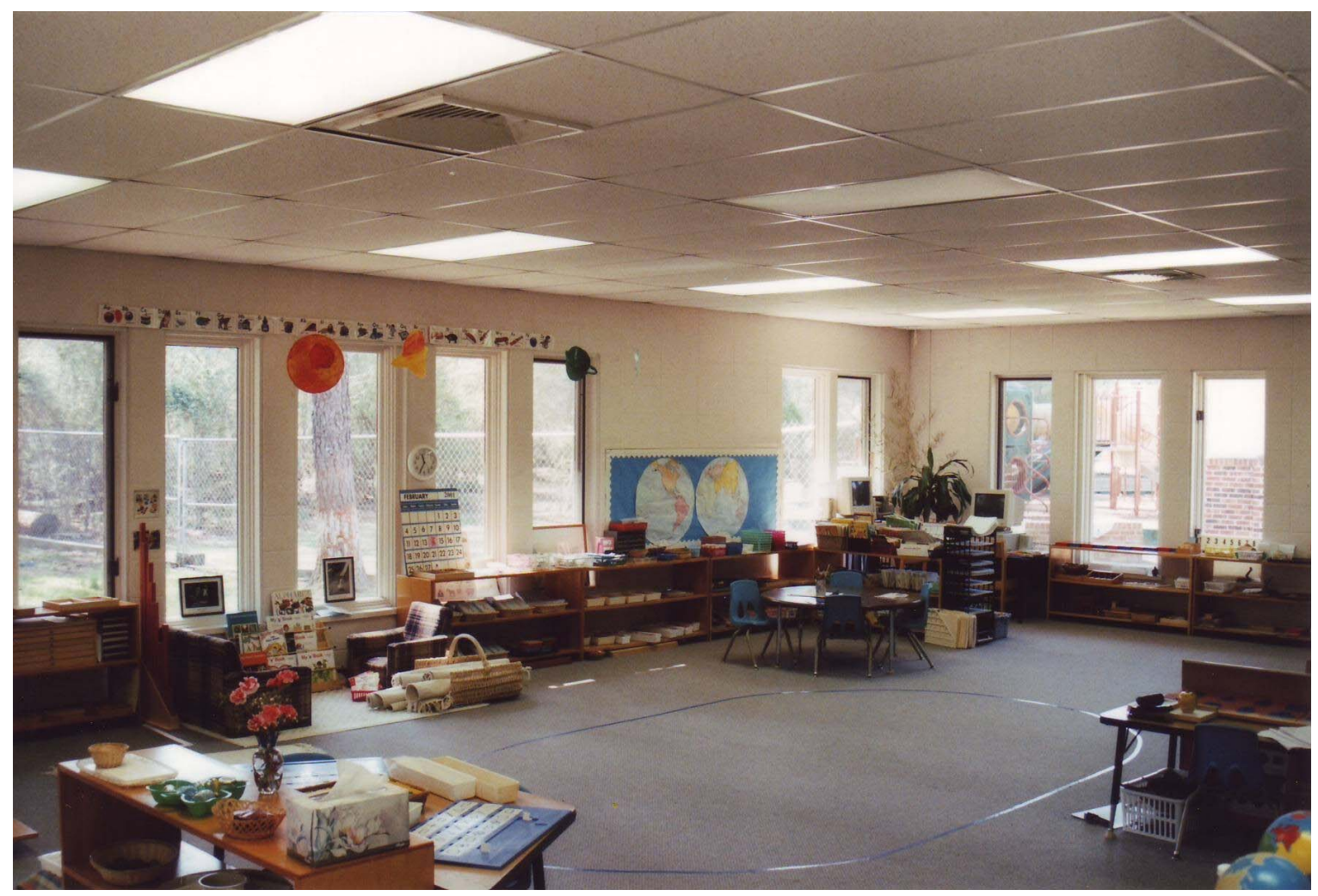

Figure 1. Classroom with low visual stimulation.

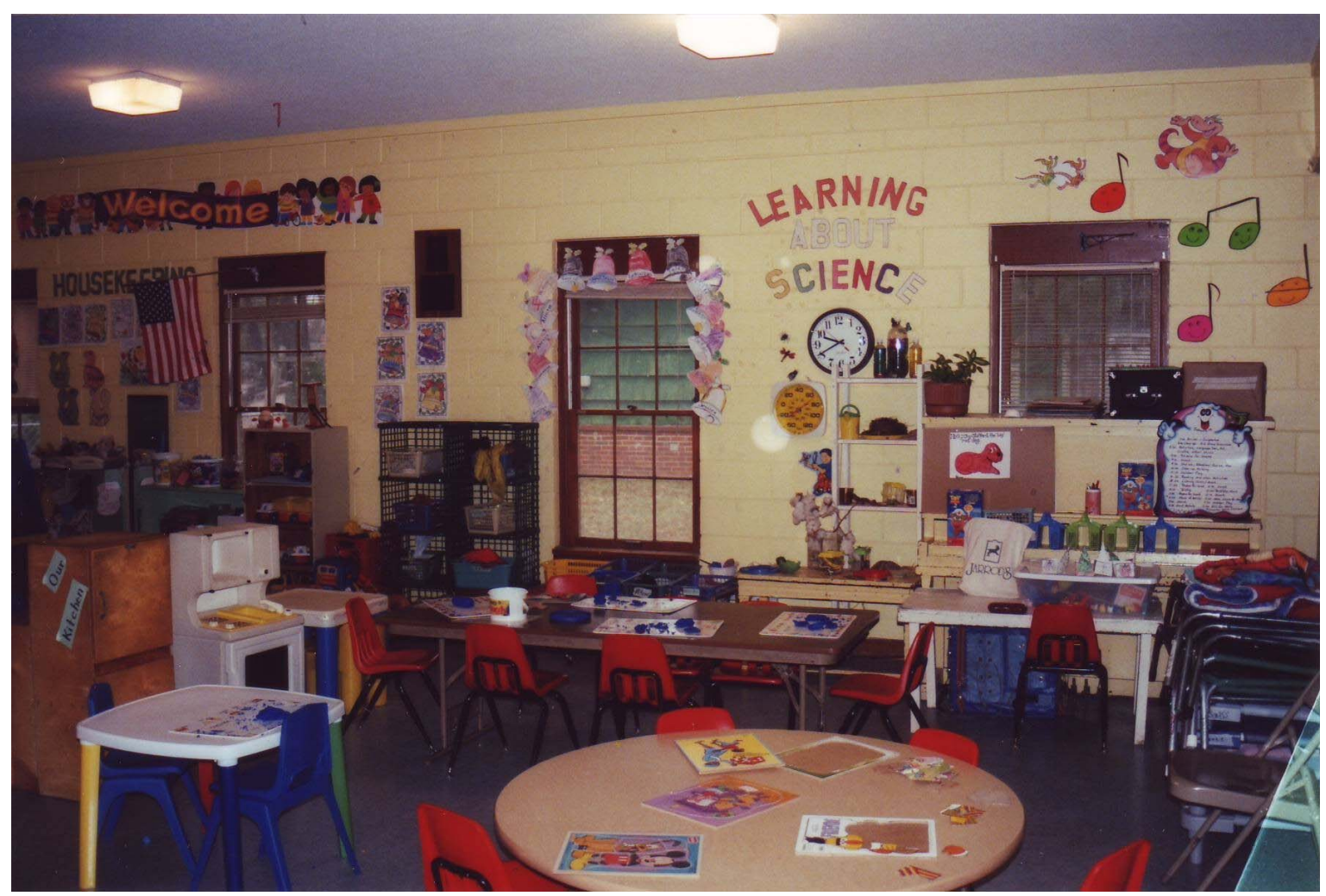

Figure 2. Classroom with high visual stimulation. 
$\boldsymbol{R}$-37 This room, because it's pretty. Well it has some pink stuff in it...I really like... this around it (pointing to paper bells around window frame in center) cause it's pink around...I really like this because it's pink around (pointing to puzzles on table). It's really kind of pink...being in this room...I could go to here...this round place. Girl

\section{Activity Materials}

$\boldsymbol{R}$-5 Points to table and chairs set. Points to puzzle on the table. I like the beautiful thing up on the wall (pointing to children's banner). The clock. Boy

R-12 Because there's more toys. Puzzle, Chairs. Girl

$\boldsymbol{R - 1 5}$ Because it's fun. Because it has a whole bunch of toys. And a whole bunch of stuff with color in it. Boy

$\boldsymbol{R}$-36 Points to the refrigerator. The window. Points to the music notes on wall. Girl.

An additional finding when comparing preference and gender was that there was a significant correlation between gender and preference for Figure 2, $t$ the high visual stimulation environment. Girls preferred the high visual stimulation environment over the low visual stimulation environment $(r=0.34, p$-value $=0.05)$. More boys reported preference for Figure 1 over Figure 2, however, the difference was not significant.

\section{Discussion}

The intent of this exploratory study was to document children's preferences for visual stimulation via the application of design principles and elements in the classroom environment. The finding that children selected circular shapes and spherical forms as special elements is of note. Circles and spheres provide variety in spaces where most elements are made up of rectilinear lines and forms. Bachelard stated "And in this rounded landscape, everything seems to be in repose" [16].

The spherical forms had special meaning to the children which they clearly stated in their responses. Possibly children felt more relaxed when viewing the spherical forms and shapes in the environment. The large-scale windows with their rectilinear shapes created dramatic rhythm within the low-stimulation environment. Children responded positively to these design elements and principles. Also of significance is the finding that girls preferred the environment with high stimulation over the low visual stimulation environment. Their descriptions of the space focused on decorative elements that created texture and rhythm in the space. Designers and teachers may wish to consider designing the environments for young children with more variety of circular shapes and spherical forms. Interest can be created simply by varying the shape in an environment to show emphasis on a form or shape through use of textures and materials. Girls may be more interested in a display area if it re- flects a high stimulation view of materials. The classroom can be balanced for open areas with less visual stimulation and more enclosed areas with more visual stimulation.

Interviewing very young children always presents certain challenges to the interviewer. At times children were not interested in completing the interview. They were occasionally bored or tired of talking with the interviewer. Most of the children, however, appeared to enjoy giving their opinions about the photographs presented to them. Their responses to the interviewer were often thoughtful and complex.

Future directions for research would be to focus on investigating a greater variety of design principles and elements within a setting such as combinations of different lines and volumes. An increased understanding of children's preferences for design in the early childhood education classroom is clearly important for designers and teachers to consider when designing a space.

\section{REFERENCES}

[1] J. Lucy "Language Diversity and Thought," Cambridge University Press, Cambridge, 1992.

[2] Y. Tuan, "Space and Place: The Perspective of Experience,” University of Minnesota Press, Minnesota, 1977.

[3] J. M. Malnar and F. Vodvarka, "Sensory Design,” University of Minnesota Press, Minnesota, 2004.

[4] J. Pile “Interior Design,” 2nd Edition, Prentice Hall, New Jersey, 1995.

[5] S. J. Slotkis, "Foundations of Interior Design,” Fairchild, New Jersey, 2006.

[6] S. S. Dazkir, "Emotional Effect of Curvilinear VS. Rectilinear Forms of Furniture in Interior Settings," Master's Thesis, Oregon State University, 2009.

[7] M. A. Read and D. Upington "Young Children's Color Preferences in the Interior Environment," Early Childhood Education Journal, Vol. 36, 2009, pp. 491-496.

[8] R. Küller and C. Lindsten, "Health and Behavior of Children in Classrooms with and without Windows," Journal of Environmental Psychology, Vol. 12, No. 4, 1992, pp. 305-317.

[9] S. Abercrombie, “A Philosophy of Interior Design,” Harper \& Row, New York, 1990.

[10] N. M. Wells "At Home with Nature: Effects of 'Greenness' on Children's Cognitive Functioning,” Environment and Behavior, Vol. 32, 2000, pp. 775-779.

[11] A. E. Boehm and R. A. Weinberg, "The Classroom Observer,” Teachers College Press, New York, 1997.

[12] T. Harms, R. M. Clifford and D. Cryer, "Early Childhood Environment Rating Scale — Revised Edition,” Teachers College Press, New York, 1998.

[13] H. Sanoff, "Creating Environments for Young Children,” Raleigh, North Carolina State University: School of De- 
sign, 1995.

[14] A. Clark, S. McQuail and P. Moss, "Exploring the Field of Listening to and Consulting with Young Children," Department of Education and Skills Research, 2003.

[15] W. L. Goodwin and L. D. Goodwin, "Understanding
Quantitative and Qualitative Research in Early Childhood Education," Teachers College Press, Report No. 445, 2006, pp. 112-114.

[16] G. Bachelard “The Poetics of Space," Beacon Press, Boston, 1964. 